\title{
A EDUCAÇÃO FÍSICA COMO COMPONENTE CURRICULAR NA EDUCAÇÃO INFANTIL E NAS SÉRIES INICIAIS DO ENSINO FUNDAMENTAL ${ }^{1}$
}

\author{
Nayara Fernanda Perles Jardim \\ Universidade Estadual de Maringá, Maringá,Paraná, Brasil. \\ Juliana Pizani \\ Universidade Estadual de Maringá, Maringá,Paraná, Brasil. \\ Fabiane Castilho Teixeira \\ Universidade Estadual de Maringá, Maringá,Paraná, Brasil. \\ Ieda Parra Barbosa Rinaldi \\ Universidade Estadual de Maringá, Maringá,Paraná, Brasil.
}

\begin{abstract}
Resumo
Este estudo objetivou investigar, por meio de pesquisa descritiva, como a educação física tem se organizado legal e pedagogicamente na educação infantil e nas séries iniciais do ensino fundamental de escolas municipais de Maringá-PR. Para a coleta de dados utilizamos questionário que foi respondido pela amostra de 16 professores de educação física. Para o tratamento dos dados recorremos à estatística descritiva e à análise de conteúdo. Os resultados indicaram que a organização legal da educação física no município investigado apresenta conformidade com a legislação vigente, sendo possível concluir que, quanto à sua organização pedagógica, a área ainda está em processo de desenvolvimento como um componente curricular, de modo a buscar seu reconhecimento pedagógico e social.
\end{abstract}

Palavras-chave: Currículo. Escola. Educação física.

\section{Introdução}

Em meados da década de 1980, a educação física passou por um período de discussão e de (re)definição nos âmbitos conceitual, epistemológico e pedagógico. Esse fato fez com que os conhecimentos da área, bem como sua sistematização para a escola, se tornassem objeto de estudo de inúmeras pesquisas (SILVEIRA; PINTO, 2001; BETTI; ZULIANI, 2002; COSTA; OLIVEIRA, 2002; ROSÁRIO; DARIDO, 2005; BARBOSARINALDI; LARA; OLIVEIRA, 2009; PALMA; OLIVEIRA; PALMA, 2010), que reco-

\footnotetext{
${ }^{1} \mathrm{O}$ presente trabalho não contou com apoio financeiro de nenhuma natureza para sua realização.
} 
nheciam a importância da organização curricular para a valorização da educação física na sociedade.

A história da educação física escolar como componente curricular obrigatório inicia-se oficialmente na década de 1990, com a promulgação da Lei de Diretrizes e Bases da Educação Nacional (LDBEN - Lei no 9.394/1996), que buscou garantir o seu reconhecimento nesse contexto, passando a assumir um papel formativo e informativo no processo educacional. Ainda de acordo com esse documento, a educação física deveria estar integrada à proposta pedagógica da escola, ajustada às diferentes faixas etárias e condições da população escolar.

Sobre o assunto, Silveira e Pinto (2001, p. 139) ressaltam que a educação física se justifica na escola, uma vez que não há outra prática pedagógica que se ocupe da dimensão específica dessa área do conhecimento, que é a cultura do movimento humano, expressa nos jogos e brincadeiras, lutas, danças, esportes e ginásticas. Nesse sentido, pensar acerca das problemáticas que envolvem a educação física escolar é uma tarefa desafiadora, haja vista que requer reflexões sobre seu papel de integrar pessoas no universo da cultura corporal de movimento, de modo significativo e responsável.

Em se tratando da educação infantil é possível notar que a partir do século XVI a sociedade passou a valorizar a infância, reconhecendo a importância da escolarização das crianças pertencentes a tal faixa etária. Nesse sentido, Garanhani (1998) e Coll (1996), sinalizam que a partir da década de 1960 ocorreram transformações significativas na educação infantil, eclodindo, além dos currículos, programas direcionados à pré-escola. No município de Maringá (PR), identifica-se a inclusão da educação física como disciplina obrigatória no currículo da educação infantil a partir da promulgação da Lei no $8.392 / 2009$. Essa determinação legal, além de procurar garantir a oferta da educação física tendo um professor específico da área como responsável, também contribuiu para seu processo de legitimação no contexto escolar.

Questionamentos no tocante à organização curricular para a educação física na escola, e o seu reconhecimento na formação do indivíduo, são assentados por diversos autores, como, Feitosa et al. (2011), Palma, Oliveira e Palma (2010), Costa e Oliveira (2002), Boscatto e Kunz (2009), Barroso e Darido (2009), entre outros. Aspectos relacionados à não legitimidade estão ligados à ausência de coerência dos conteúdos selecionados, que objetivam promover a leitura crítica da sociedade, isso porque falta uma organização curricular da educação física, tornando-a por vezes desconexa da realidade do aluno. Com isso destacamos a importância de estudos sobre a elaboração e prática do currículo escolar, com vistas ao desenvolvimento do processo ensino-aprendizagem.

A produção teórica sobre currículo, apresentada por autores como Apple (2006) e Gimeno Sacristán (2013), expõe uma visão crítica acerca da sua constituição nos contextos em que são consolidados, apontando para a necessidade de compreensão das relações estabelecidas e das suas formas de institucionalização, a fim de superar a concepção puramente burocrática e racional de ordenamento do ensino. Sendo assim, é importante reconhecer a organização curricular como um processo em constante desenvolvimento, que precisa acompanhar toda transformação e dinâmica social.

No âmbito escolar é possível identificar a dificuldade histórica relacionada ao planejamento e à sistematização da ação interventiva docente presente na área da educação física. Castro, Tucunduva e Arns (2008, p. 53) destacam que "o planejamento serve como 
uma ferramenta importantíssima para organizar e subsidiar o trabalho do professor". Corroborando com Veiga (1995), o planejamento deve ir além de um agrupamento de planos de ensino e atividades diversas, não devendo ser algo construído e arquivado, mas sim efetivado durante todo o processo educacional.

Por esses aspectos, na consolidação da organização curricular, o planejamento pedagógico se apresenta como elemento que pode nortear as ações escolares. Gemerasca e Gandim (2004) entendem o planejamento pedagógico como suporte para o encaminhamento das mudanças necessárias, que pode contribuir para concretizar o almejado e cria possibilidades de intervir na realidade.

Diante dos pressupostos apresentados, indagamos: de que forma a educação física como componente curricular na educação infantil e nas séries iniciais do ensino fundamental tem se organizado na cidade de Maringá (PR)? Como os professores têm encaminhado suas ações de elaboração do projeto pedagógico e planejamento das aulas, e quais os principais desafios apresentados nesse processo?

Assim, este estudo teve por objetivo investigar, por meio de pesquisa descritiva, como a educação física tem se organizado legal e pedagogicamente na educação infantil e nas séries iniciais do ensino fundamental de escolas municipais de Maringá (PR). Com essa pesquisa, esperamos fornecer subsídios para enriquecer o debate acerca da temática, ampliando possibilidades de entendimento e intervenção no universo escolar, para a construção de uma realidade favorável à presença da educação física na escola.

\section{Metodologia}

Para alcançar o objetivo proposto, a opção metodológica foi pela pesquisa descritiva, entendida por Cervo e Bervian (1996, p. 49) como "[...] aquela que observa, registra, analisa e correlaciona fatos ou fenômenos (variáveis) sem manipulá-los".

Tomamos como foco do estudo escolas municipais da cidade de Maringá (PR) que oferecem o ensino em nível de educação infantil e das séries iniciais do ensino fundamental (1ํa a 5aa), bem como os professores de educação física.

De acordo com a Secretaria de Educação do Paraná, o município de Maringá conta atualmente com 56 centros municipais de educação infantil e 50 escolas municipais, totalizando 106 escolas da rede municipal de ensino. Participaram da pesquisa oito centros infantis e oito escolas municipais, sendo representados por 16 professores de educação física no total.

A redução da amostra deu-se em razão da determinação da Secretaria de Educação de Maringá (Seduc) com relação ao número de instituições que poderiam ser pesquisadas, assim como em quais delas o estudo poderia ser realizado. Outro aspecto é que a Seduc indicou as escolas que já contavam com professores de educação física contratados, visto que em parte das escolas a efetivação da contratação ainda não havia acontecido.

A fonte de dados foi composta por questionário, constituído por questões abertas e fechadas, aplicado aos professores de educação física desses níveis de ensino, de forma individualizada.

Para o tratamento dos dados utilizamos estatística descritiva, em especial para as questões fechadas, e recorremos à análise de conteúdo proposta por Bardin (1977), para a análise das questões abertas. Para tanto, aplicamos a unidade de significado, entendida 
como sendo o "menor recorte de ordem semântica que se liberta do texto" (BARDIN, 1977, p. 104). A autora apresenta a unidade de significação como correspondente ao segmento de conteúdo considerado como unidade de base, visando a sua categorização e a contagem frequencial. Dessa forma, empregamos a análise categorial, dentre as várias possibilidades de categorização, a qual "consiste em descobrir núcleos de sentido que compõem a comunicação e cuja presença, ou frequência de aparição podem significar alguma coisa para o objetivo analítico escolhido" (BARDIN, 1977, p. 105).

Essa pesquisa foi submetida à aprovação no Comitê Permanente de Ética em Pesquisa (Copep), e foi aprovada pelo Parecer no 48032/2012.

\section{Resultados e discussão}

Para uma melhor compreensão da realidade da educação física escolar, a presente pesquisa foi realizada a partir da análise da organização dessa disciplina como componente curricular da educação infantil e das séries iniciais do ensino fundamental. Dessa forma, os dados foram categorizados e distribuídos em quadros que são apresentados no decorrer do texto.

A elaboração do projeto pedagógico é de responsabilidade da própria escola, que, além de atender à legislação vigente, é importante construí-lo coletivamente, com a participação de toda comunidade escolar (direção, professores, alunos e pais), para que se caminhe rumo a sua legitimação. Sobre o assunto, Mota e Silva e Venâncio (2008) destacam que o projeto pedagógico precisa conter os objetivos da escola, suas prioridades, necessidades e ações, sendo, portanto, uma oportunidade para a instituição escolar selecionar os aspectos considerados fundamentais para seu desenvolvimento.

Assim, o Quadro 1 contempla as categorias acerca da participação dos professores no processo de elaboração do projeto pedagógico. Como resultado, constatamos que em todas as escolas pesquisadas havia um projeto pedagógico, indicando que estas possuem um documento que representa, de acordo com Soares et al. (2009), as estratégias e intenções para ações escolares. Também ratifica o cumprimento do que é ressaltado na

Lei de Diretrizes e Bases da Educação Nacional (Lei no 9.394/1996), que preconiza a elaboração e execução da proposta pedagógica da escola.

Quadro 1. Categorização referente à participação dos professores no processo de elaboração do projeto pedagógico.

\begin{tabular}{|l|l|c|c|}
\hline \multicolumn{1}{|c|}{ CATEGORIA } & $\begin{array}{c}\text { Unidades de } \\
\text { Significado } \\
\text { (US) }\end{array}$ & $\begin{array}{c}\text { Somatória } \\
\text { da } \boldsymbol{f} \text { das US }\end{array}$ \\
\hline 1 & $\begin{array}{l}\text { Reuniões de professores de educação física para planeja- } \\
\text { mento }\end{array}$ & $1,2,3$ e 6 & 11 \\
\hline 2 & Estudos individuais e coletivos & $4,5,7$ e 8 & 12 \\
\hline
\end{tabular}

Podemos observar no Quadro 1 que a participação dos professores se deu, sobretudo, por meio de reuniões com o intuito de elaborar o projeto pedagógico (categoria 1 , 
$f=11$ ), bem como estudos coletivos e individualizados (categoria $2, f=12$ ) realizados anteriormente para embasar as discussões e contribuir com a ação de planejamento. Esse trabalho coletivo por meio de estudos e reuniões torna-se válido por proporcionar troca de experiências entre os docentes; construção conjunta de conhecimentos que atenderão aspectos fundamentais para constituir o projeto pedagógico, como a escolha de objetivos ou metas a serem alcançadas; decisões acerca dos conteúdos a serem trabalhados; e seleção de métodos/processos adequados (KELLY, 1981).

Sobre o processo de elaboração do projeto pedagógico, autores como Veiga (1995), Ghedin (2006), Sacristán (2013), entre outros, apontam que os professores são agentes indispensáveis para o planejamento coletivo. Além disso, ressaltamos a importância de toda a comunidade escolar para a realização de um projeto com valor educacional.

Entretanto, vale salientar que mesmo sendo identificada uma organização docente com o objetivo de construir o PP, esse processo se mostra em desenvolvimento, visto que $31,2 \%$ dos professores pesquisados não participaram da elaboração desse documento, demonstrando que ainda é preciso galgar passos para a consolidação do processo. É preciso considerar que, em muitos casos, o projeto pedagógico já existe anteriormente à contratação do docente, não havendo a possibilidade de participação efetiva, especialmente no caso da educação infantil no município de Maringá, devido à recente inclusão da educação física como disciplina obrigatória nesse nível de ensino (Lei no 8.392/2009).

Alertamos, portanto, para a importância de uma política escolar que possibilite a inclusão dos docentes recém-contratados no processo e/ou seu contato direto e contínuo com o planejamento escolar, buscando legitimação para que ele seja efetivado na prática. E para além de uma ação burocrática, o currículo deve ser constantemente revisado, a fim de atender às necessidades escolares, no que concerne a toda comunidade envolvida (diretores, professores, pedagogos, pais, alunos, etc.) (SACRISTÁN, 2013).

No que se refere à utilização de documentos para a elaboração do projeto pedagógico, identificamos que $68,8 \%$ dos professores recorreram a documentos como base para a elaboração do projeto pedagógico, e $31,2 \%$ não, devido ao fato de não terem participado do processo de construção do PP. Esse embasamento pode indicar que os projetos pedagógicos estão em conformidade com os documentos legais da área. Contudo, quando questionamos os professores sobre quais documentos foram utilizados, notamos uma baixa frequência de aparição das respostas em relação aos documentos tidos como primordiais, o que, por vezes, se constitui em um cenário contrário aos $68,8 \%$ que emitiram parecer positivo quanto ao uso dos aspectos jurídicos. Esse mapeamento pode ser observado no Quadro 2. 
Quadro 2. Categorização referente à utilização de documentos para a elaboração do projeto pedagógico.

\begin{tabular}{|l|l|c|c|}
\hline n & \multicolumn{1}{|c|}{ CATEGORIA } & $\begin{array}{c}\text { Unidades de } \\
\text { Significado } \\
\text { (US) }\end{array}$ & $\begin{array}{c}\text { Somatória } \\
\text { da } \boldsymbol{f} \text { das US }\end{array}$ \\
\hline 1 & $\begin{array}{l}\text { Diretrizes curriculares da educação básica do estado do } \\
\text { Paraná }\end{array}$ & 1 & 10 \\
\hline 2 & $\begin{array}{l}\text { Diretrizes curriculares para a educação infantil do estado } \\
\text { do Paraná }\end{array}$ & 2 & 4 \\
\hline 3 & Constituição Federal de 1988 & 3 & 1 \\
\hline 4 & LDBEN no 9.394/96 & 4 & 1 \\
\hline 5 & Estatuto da Criança e do Adolescente (ECA) & 6 & 1 \\
\hline 6 & Parâmetros Curriculares Nacionais (PCNs) & 7 & 6 \\
\hline 7 & Livros e artigos com foco na pedagogia histórico-crítica & $8,9,10,11 \mathrm{e}$ & 5 \\
\hline 8 & Não houve a utilização de nenhum documento como base & 12 & 3 \\
\hline
\end{tabular}

Como ponto de destaque do Quadro 2, citamos as categorias 3 e 4, que representam os documentos legais a serem atendidos, Constituição Federal de 1988 e LDBEN no 9.394/1996. Contudo, a baixa frequência com que foram citadas, pode indicar que as instituições de ensino pesquisadas não contemplam o atendimento legal em sua totalidade, mesmo que tenhamos maior representatividade nas categorias 1 e 2 , que expressam a utilização das diretrizes específicas para cada etapa de ensino (educação infantil e ensino fundamental), as quais norteiam não só a elaboração do projeto pedagógico, mas também os planejamentos de aulas.

Para além do exposto, e não menos importante, é o fato de a categoria $8(f=3)$ ter apontado que nenhum documento balizou a construção do currículo. É importante frisar, de acordo com Llavador (2013), que o currículo, entendido como projeto pedagógico, deve atender aos aspectos jurídicos que estabelecem regras, como as leis, decretos, resoluções etc., e que, portanto, faz-se necessária a utilização destes como base para a construção do projeto pedagógico da escola, para que o ele declare sua licitude perante os órgãos legislativos. O que assinala que o currículo deve ser mais do que somente uma coleção aleatória de conhecimentos organizados para sua transmissão.

Os professores também demonstraram necessidade de recorrer a livros e artigos para fundamentar a pedagogia histórico-crítica, visto que esta é a proposta que baliza as diretrizes curriculares do estado do Paraná da educação básica, bem como a da rede municipal de ensino de Maringá (PR). Isso pode estar relacionado com o fato de a pedagogia histórico-crítica ser abordagem pedagógica adotada pela Secretaria Municipal de Educação de Maringá (SEDUC). Vale ressaltar que essa abordagem é proposta por Saviani, tendo seu embasamento teórico fundamentado no materialismo histórico-dialético, além de apresentar suas bases psicológicas na psicologia histórico-cultural, desenvolvida por $\mathrm{Vy}$ gotsky. 
No que se refere à presença da educação física como componente curricular no projeto pedagógico, 93,8\% dos professores alega que isso se efetiva. Esse dado pode indicar que os centros infantis pesquisados estão de acordo com a Lei municipal $\mathrm{n}$ o $8.392 / 2009$, que determina a inclusão da educação física como disciplina obrigatória no currículo da educação infantil, cabendo ao município promover a capacitação de pessoal docente. $\mathrm{O}$ embate que se trava acerca da educação física como componente curricular obrigatório, bem como a seleção organizada dos conteúdos a serem trabalhados, tem sido amplamente estabelecido ao longo dos anos (BARROSO; DARIDO 2009; FREIRE et al. 2010; PALMA; OLIVEIRA; PALMA, 2010; FEITOSA et al., 2011).

Com isso, o professor de educação física passa a ser o responsável por ministrar esse componente curricular na educação infantil, evidenciando um avanço com relação à legitimidade e legalidade da área no espaço escolar. Isso porque, até a promulgação da Lei no 8.392/2009, no município de Maringá-PR, quem se responsabilizava pelo trabalho concernente à educação física era o pedagogo, pois não havia a necessidade de uma formação específica.

O ensino fundamental já contemplava a educação física como disciplina obrigatória, em conformidade com a LDBEN (Lei no 9.394/1996), que estabelece a educação física como componente curricular da educação básica e não mais como atividade. Nesse sentido, as Diretrizes Curriculares do Estado do Paraná para a educação básica também assumem a educação física como parte do projeto geral de escolarização, devendo estar articulada ao projeto pedagógico. Este documento defende que as aulas de educação física não podem ser consideradas como apêndices das demais atividades escolares, tampouco um momento compensatório delas (PARANÁ, 2008).

A partir da compreensão da educação física como disciplina escolar, identificamos que

$100 \%$ dos professores pesquisados apontam que a educação física se faz presente no projeto pedagógico como componente curricular. Sobre o assunto, também obtivemos algumas categorias, como apresentado no Quadro 3.

Quadro 3. Categorização referente à presença da educação física na escola na opinião dos professores.

\begin{tabular}{|c|l|c|c|}
\hline & \multicolumn{1}{|c|}{ CATEGORIA } & $\begin{array}{c}\text { Unidades de } \\
\text { Significado } \\
\text { (US) }\end{array}$ & $\begin{array}{c}\text { Somatória } \\
\text { da } \boldsymbol{f} \text { das US }\end{array}$ \\
\hline 1 & $\begin{array}{l}\text { Disciplina indispensável para a formação e o desenvolvi- } \\
\text { mento integral do aluno }\end{array}$ & $1,2,5$ & 7 \\
\hline 2 & Auxiliar na aprendizagem de outras disciplinas escolares & 3 & 1 \\
\hline 3 & $\begin{array}{l}\text { Necessidade de mais estudos e transformações, em espe- } \\
\text { cial por ser recente na educação infantil }\end{array}$ & 4 e 6 & 3 \\
\hline 4 & $\begin{array}{l}\text { Cultura corporal como conhecimento historicamente } \\
\text { construído pelo ser humano }\end{array}$ & 7 & 1 \\
\hline 5 & $\begin{array}{l}\text { Importante, pois o corpo é fundamental para o processo } \\
\text { de constituição da criança como sujeito cultural }\end{array}$ & 8 & 4 \\
\hline
\end{tabular}


Nota-se no Quadro 3 que a categoria $1(f=7)$ mostra associação da educação física à formação integral dos alunos. Tomando a educação infantil e as séries iniciais como foco, faz-se importante oportunizar a vivência de diferentes possibilidades corporais, pois o corpo assume um papel fundamental no processo de constituição da criança como sujeito cultural (categoria 5). Isso porque, nessa faixa etária em especial, o movimentar-se é constituinte do processo de compreensão e expressão de significados presentes no contexto histórico-cultural em que se encontra.

Desse modo, ao tratar a respeito do desenvolvimento infantil, conclui-se, a partir da teoria de Vygotsky (1984), que é por meio da socialização que a criança estabelece relações com o meio, interagindo com outras crianças e adultos, o que poderá contribuir efetivamente para o seu desenvolvimento.

Os professores também identificam a presença da educação física na escola como sendo representante de um conhecimento historicamente construído pelo ser humano, sendo constituída pela cultura corporal. De acordo com Soares et al. (2009), ao tratar de uma reflexão sobre a cultura corporal, os autores indicam que constituem parte de um acervo de diversas formas de representação do mundo, produzidas pelo homem no decorrer da história, culturalmente desenvolvidas e exteriorizadas por meio da expressão corporal.

Ainda vale destacar que os professores da educação física infantil declaram que há necessidade de mais estudos e transformações, pois a Lei no 8.292/2009 ainda se apresenta em fase de desenvolvimento, por ter sido implementada recentemente.

Sobre o planejamento de aulas, os participantes do estudo, em sua totalidade, afirmam sua efetivação, sendo considerado como fator importante para a legitimação da educação física escolar, uma vez que Silva (2004) entende a ação de planejar como indispensável para a organização da prática docente, além de ser um momento permeado por reflexões e avaliação sobre o processo de ensino-aprendizagem, o qual constitui-se por uma intenção política que visa intervir na realidade escolar dos alunos.

Identificamos também que todos professores alegaram que são realizadas reuniões para discutir coletivamente a educação física, e que muitas delas são organizadas pela própria Secretaria de Educação do município. Com base em Veiga (1995), ao assumir a discussão e elaboração coletiva, busca-se o aperfeiçoamento da qualidade do processo de ensino-aprendizagem. Isso porque contribuem para o aprimoramento da prática pedagógica por meio de problematizações, reflexões, trocas de experiências, produção de conhecimento, entre outros aspectos concernentes ao cotidiano escolar.

Partindo do pressuposto de que a falta de sistematização dos conhecimentos trabalhados nas aulas de educação física pode ser um fator coadjuvante à sua não legitimação no contexto escolar, podendo, ainda, resultar em falta de consistência do processo de ensino-aprendizagem desenvolvido, questionamos os professores sobre a seleção dos conhecimentos a serem trabalhados nas aulas. As categorias referentes a essa questão são demonstradas no Quadro 4.

Pensar a Prática, Goiânia, v. 17, n. 4, out./dez. 2014 
Quadro 4. Categorização referente ao planejamento e seleção dos conhecimentos a serem trabalhados nas aulas.

\begin{tabular}{|c|l|c|c|}
\hline & \multicolumn{1}{|c|}{ CATEGORIA } & $\begin{array}{c}\text { Unidades de } \\
\text { Significado } \\
\text { (US) }\end{array}$ & $\begin{array}{c}\text { Somatória } \\
\text { da } \boldsymbol{f} \text { das US }\end{array}$ \\
\hline 1 & É realizado nas reuniões da Seduc & 1 e 2 & 14 \\
\hline 2 & $\begin{array}{l}\text { Embasado no projeto pedagógico e na proposta curricular } \\
\text { da rede municipal }\end{array}$ & 3,6 e 7 & 5 \\
\hline 3 & O desenvolvimento integral do aluno & 4,5 & 7 \\
\hline 4 & $\begin{array}{l}\text { Faixa etária, recursos físicos e materiais, necessidades da } \\
\text { turma/aluno e diversidade de conteúdos da educação físi- } \\
\text { ca }\end{array}$ & 8,9 e 10 & 11 \\
\hline 5 & A relevância social do conteúdo & 11 & 5 \\
\hline
\end{tabular}

É possível identificar no Quadro 4 que a categoria $1(f=14)$ demonstra que o planejamento dos conteúdos a serem trabalhados nas aulas são definidos nas reuniões realizadas na Secretaria de Educação de Maringá, contando com a participação de todos os professores de educação física da rede municipal de ensino.

Um ponto de destaque é que os resultados sugerem que os professores da educação infantil e das séries iniciais do ensino fundamental apresentam compreensões diferentes acerca da efetivação do planejamento coletivo. Isto se evidencia pelo fato de os professores da educação infantil afirmarem que selecionam e organizam os conteúdos de acordo com o projeto pedagógico. Já os professores das séries iniciais do ensino fundamental parecem aceitar a flexibilidade no processo de planejamento cotidiano das aulas, haja vista o entendimento de que cada professor, após o planejamento coletivo, pondere sua característica pessoal no momento de aplicar as aulas.

Ressaltamos que se trata de uma problemática evidenciada no âmbito escolar, uma vez que essa flexibilidade pode acabar por contribuir para a falta de sistematização dos conhecimentos a serem trabalhados nas aulas. Os entraves acerca da elaboração e aplicação do planejamento coletivo foram também evidenciados em pesquisa desenvolvida por Oliveira et al. (2011), na rede pública de ensino de Maringá-PR, a qual revelou que, apesar de os professores de educação física participarem coletivamente da elaboração do PP e o considerarem um eixo norteador das ações, apresentam dificuldades na extensão dos seus objetivos para o campo prático. Outro estudo que aponta tal problemática foi realizado por Bossle (2003), na rede municipal de ensino de Porto Alegre-RS, o qual indicou que no processo desenvolvido, os professores de educação física acabaram considerando o planejamento como uma atividade burocrática a ser realizada no início do ano letivo, não percebendo sua aplicabilidade no cotidiano escolar.

Os resultados apresentados refletem esse quadro e sugerem a importância da sistematização dos conhecimentos trabalhados nas aulas de educação física. Os dados também demonstram que essa organização ainda se encontra em desenvolvimento, confirmando que a questão precisa ser debatida e refletida pela área, tendo em vista, entre outros aspectos, o seu reconhecimento social. 
Vale elucidar que os professores da área vêm apresentando dificuldades nesse quesito, demonstrando dúvidas com relação ao que ensinar, quando e para que ensinar em cada uma das séries. Talvez isso esteja relacionado ao fato da educação física ainda não possuir uma sistematização curricular, o que pode propiciar o surgimento de dúvidas e procedimentos de ensino desarticulados e sem organização adequada dos conteúdos, tornando-se sem sentido e sem significado para os alunos (PALMA; OLIVEIRA; PALMA, 2010).

É necessário destacar que a educação física é significativa para a formação dos alunos, já que possui uma gama de conhecimentos a serem sistematizados nas aulas. Assim, é importante que a educação física, como componente curricular obrigatório, seja organizada e desenvolvida de forma apropriada na escola, tendo por objetivo a formação crítica e reflexiva dos educandos, contribuindo para a legitimidade da área.

\section{Conclusões}

O desenvolvimento desta pesquisa possibilitou-nos conhecer a educação física como componente curricular na educação infantil e nas séries iniciais do ensino fundamental na cidade de Maringá-PR. No decorrer deste estudo, discutimos como se dá a participação dos professores no processo de elaboração do projeto pedagógico e a organização da educação física no espaço escolar das instituições pesquisadas, o que nos leva às seguintes constatações:

$\checkmark$ Foi possível identificar que as escolas participantes da pesquisa possuem um projeto pedagógico e que a educação física é contemplada como componente curricular. Ademais, na elaboração do projeto, notou-se participação efetiva dos professores de educação física pesquisados da rede municipal de ensino de Maringá-PR, o que indica preocupação com o processo educacional.

$\checkmark$ Constatou-se a realização de reuniões pedagógicas pela Secretaria de Educação de Maringá, as quais são direcionadas à construção da proposta curricular que compõe o projeto pedagógico das escolas, com o intuito de que ele se coloque como documento orientador da prática pedagógica cotidiana.

Mesmo havendo ações docentes, ainda se faz necessária a existência de uma política escolar que possibilite a participação de todos os professores no processo de construção e/ou contato direto com o projeto pedagógico.

$\checkmark$ Verificou-se também a utilização de documentos como base no processo de elaboração do projeto pedagógico, demonstrando conformidade com as políticas educacionais presentes nas leis, na Constituição Federal de 1988, na LDBEN 9.394/1996, no Estatuto da Criança e do Adolescente. Entretanto, embora tenham sido utilizados documentos oficiais, eles não balizaram por completo a construção do projeto, visto que poucos docentes elencaram sua utilização.

Pensar a Prática, Goiânia, v. 17, n. 4, out./dez. 2014 
$\checkmark$ Destaca-se a dificuldade dos professores com a sistematização dos conteúdos a serem trabalhados, indicando que ainda é preciso galgar passos para a consolidação do processo de estruturação e efetivação do planejamento coletivo no âmbito escolar.

Conclui-se que a organização legal da educação física no município investigado apresenta conformidade com a legislação vigente. No tocante à sua organização pedagógica, a área ainda está em processo de desenvolvimento como um componente curricular, de modo a buscar seu reconhecimento social.

Contudo, a compreensão mais aprofundada da realidade da educação física escolar exigirá a utilização de procedimentos adicionais de pesquisa que, neste estudo, não foram contemplados, tais como pesquisas do tipo longitudinais que possam acompanhar o desenvolvimento do processo de legitimação da área.

\title{
PHYSICAL EDUCATION AS CURRICULAR COMPONENT IN THE CHILD REARING AND IN THE INITIAL SERIES OF PRIMARY EDUCATION
}

\begin{abstract}
This research aimed to investigate, by means of descriptive research, as physical education has been organized legally and pedagogically in the child rearing and in the initial series of primary education at public schools of Maringá-PR. For collect the data we use questionnaire that was answer by the sample of 16 physical education teachers. For data processing we used the descriptive statistics and content analysis. The results indicated that the legal organization of physical education in the municipality investigated is compliant with current legislation, is possible to conclude that for their pedagogical organization, the area is still under development as a curriculum component, in order to seek pedagogical and social recognition.
\end{abstract}

Keywords: Curriculum. School. Physical Education.

\section{EDUCACIÓN FÍSICA COMO COMPONENTE CURRICULAR EN LA EDUCACIÓN DE LA PRIMERA INFANCIA Y EN LA SERIE INICIAL DE EDUCACIÓN PRIMARIA}

\section{Resumen}

Esta investigación tuvo como objetivo investigar, por medio de la investigación descriptiva, como la educación física ha sido organizada legalmente y pedagógicamente en la educación de la primera infancia y en la serie inicial de educación primaria en escuelas públicas de Maringá-PR. Para recopilar los datos utilizamos cuestionario que fue respondido por la muestra de 16 profesores de educación física. Para el procesamiento de los datos se utilizó estadística descriptiva y análisis de contenido. Los resultados indicaron que la organización jurídica de la educación física en el municipio investigado cumple con la legislación vigente, es posible concluir que cuanto a su organización educativa, el área está todavía en desarrollo como un componente del currículo, con el fin de buscar el reconocimiento pedagógico y social.

Palabras clave: Curriculum. Escuela. Educación Física.

Pensar a Prática, Goiânia, v. 17, n. 4, out./dez. 2014 


\section{Referências}

APPLE, M. W. Ideologia e currículo. 3. ed. Porto Alegre: Artmed, 2006.

BARBOSA-RINALDI, I. P.; LARA, L. M.; OLIVEIRA, A. A. B. O. Contribuições ao processo de (re)significação da educação física escolar: dimensões das brincadeiras populares, da dança, da expressão corporal e da ginástica. Movimento, Porto Alegre, v. 15, n. 4, p. 217-242, out./dez. 2009.

BARDIN, L. Análise de conteúdo. Lisboa: Edições 70, 1977.

BARROSO, A. L. R.; DARIDO, S. C. A pedagogia do esporte e as dimensões dos conteúdos: conceitual, procedimental e atitudinal. Revista da Educação Física/UEM, Maringá, v. 20, n. 2, p. 281-289, 2. trim. 2009.

BETTI, M.; ZULIANI, L. R. Educação Física escolar: uma proposta de diretrizes pedagógicas. Revista Mackenzie de Educação Física e Esporte, São Paulo, ano 1, n. 1, p. 73-81, 2002.

BOSCATTO, J. D.; KUNZ, E. Didática comunicativa: contribuições para a legitimação pedagógica da educação física escolar. Revista da Educação Física/UEM, Maringá, v. 20, n.2, p. 183-195, 2. trim. 2009.

BOSSLE, F. Planejamento de ensino dos professores de educação física do $2^{\circ}$ e $3^{\circ}$ ciclos da rede municipal de ensino de Porto Alegre: um estudo do tipo etnográfico em quatro escolas desta rede de ensino. 2003. 273 f. Dissertação (Mestrado em Educação Física) - Curso de Educação Física, Departamento de Educação Física, UFRGS, Porto Alegre, 2003.

BRASIL. Ministério da Educação. Lei de diretrizes e bases da educação nacional n. 9.394, de 20 de dezembro de 1996. Diário Oficial da União, Brasília, DF, 20 dez. 1996.

CASTRO, P. A. P. P. de; TUCUNDUVA, C. C.; ARNS, E. M. A importância do planejamento das aulas para organização do trabalho do professor em sua prática docente. Athena - Revista Científica de Educação, Curitiba, v. 10, n. 10, p. 49-62, jan./jun. 2008.

CERVO, A. L.; BERVIAN, P. A. Metodologia científica: para uso dos estudantes universitários. São Paulo: McGraw-Hill do Brasil, 1996.

COLL, C. Psicologia e currículo: uma aproximação psicopedagógica à elaboração do currículo escolar. São Paulo: Ática, 1996.

COSTA, J. C. K.; OLIVEIRA, A. A. B. O eixo movimento na educação infantil: uma proposta de planejamento. Revista da Educação Física/UEM, Maringá, v. 13, n. 1, p. 115121, 1. sem. 2002.

Pensar a Prática, Goiânia, v. 17, n. 4, out./dez. 2014 
FEITOSA, W. M. N. et al. Aulas de educação física no ensino médio da rede pública estadual de Caruaru: componente curricular obrigatório ou facultativo? Revista da Educação Física/UEM, Maringá, v. 22, n. 1, p. 97-109, 1. trim. 2011.

FREIRE, E. S. et al. A dimensão atitudinal nas aulas de educação física: conteúdos selecionados pelos professores. Revista da Educação Física/UEM, Maringá, v. 21, n. 2, p.223-235, 2. trim. 2010.

GARANHANI, M. C. A educação motora no currículo da educação infantil da rede municipal de ensino de Curitiba. 2006. 79 f. Dissertação (Mestrado em Educação) Universidade Federal do Paraná, Curitiba, 1998.

GEMERASCA, M. P.; GANDIN, D. Planejamento participativo na escola: o que é e como se faz. 3. ed. São Paulo: Loyola, 2004.

GHEDIN, E. Professor reflexivo: da alienação da técnica à autonomia da crítica. In: PIMENTA, S. G.; GHEDIN, E. (Org.). Professor reflexivo no Brasil: gênese e crítica de um conceito. 4. ed. São Paulo: Cortez, 2006.

KELLY, A. V. O currículo: teoria e prática. São Paulo: Harper \& Row do Brasil, 1981.

LLAVADOR, F. B. Política, poder e controle do currículo. In: GIMENO SACRISTÁN, J. Saberes e incertezas sobre o currículo. Porto Alegre: Penso, 2013. p. 38-53.

MARINGÁ (PR). Lei no 8.392, de 22 de julho de 2009. Maringá, PR, 2009.

MOTA E SILVA, E. V.; VENÂNCIO, L. Aspectos legais da educação física e integração à proposta pedagógica da escola. In: DARIDO, S. C.; RANGEL, I. C. A. Educação física na escola: implicações para a prática pedagógica. Rio de Janeiro: Guanabara Koogan, 2008.

OLIVEIRA, A. A. B. et al. Projeto Político Pedagógico: elaboração e aplicação nas escolas públicas de Maringá. Movimento, Porto Alegre, v. 17, p. 77-94, 2011.

PALMA, A. P. T. V.; OLIVEIRA, A. A. B.; PALMA, J. A. V. Educação física e a organização curricular: educação infantil, ensino fundamental e ensino médio. 2. ed. Londrina: Eduel, 2010.

PARANÁ. Secretaria de Estado da Educação. Diretrizes curriculares da educação básica: educação física. Curitiba: SEED, 2008.

ROSÁRIO, L. F. R.; DARIDO, S. C. A sistematização dos conteúdos da educação física na escola: a perspectiva dos professores experientes. Motriz, Rio Claro, v. 11, n. 3, p. 167-178, set./dez. 2005. 
SACRISTÁN, J. G. O que significa o currículo? In: GIMENO SACRISTÁN, J. Saberes e incertezas sobre o currículo. Porto Alegre: Penso, 2013. p. 16-35.

SILVA, H. L. F. Planejamento escolar e legitimidade da educação física após a regulamentação da profissão: profissional - indivíduo ou professor da categoria? Revista Mackenzie de Educação Física e Esporte, São Paulo, ano 3, n. 3, p. 77-88, 2004.

SILVEIRA, G. C. F.; PINTO, J. F. Educação Física na perspectiva da cultura corporal: uma proposta pedagógica. Revista Brasileira Ciências do Esporte, Florianópolis, v. 22, n. 3, p. 137-150, maio 2001 .

SOARES, C. L. et al. Metodologia do ensino de educação física. São Paulo: Cortez, 2009.

VEIGA, I. P. A. Projeto político-pedagógico da escola: uma construção possível. 11. ed. Campinas: Papirus, 1995.

VYGOTSKY, L. S. A formação social da mente. São Paulo: Martins Fontes, 1984.

Recebido em: 25/07/2014

Revisado em: 10/10/2014

Aprovado em: 16/10/2014

Endereço para correspondência:

parrarinaldi@hotmail.com

Ieda Parra Barbosa-Rinaldi

Universidade Estadual de Maringá.

v. Colombo, 5790 - Campus Universitário - Dep. de Educação Física

Zona 7

87020900 - Maringa, PR - Brasil

Pensar a Prática, Goiânia, v. 17, n. 4, out./dez. 2014 